\title{
Bulgarian Experience in Use of Internet for Production and Business Applications
}

Todor Neshkov -assoc. prof., Dean, Faculty of Mechanical Engineering

Julian Pankov - postgraduate student in TU - Sofia

\begin{abstract}
This paper is directed to the problems liked with presentation of production and trade enterprise in Internet. Specialised WEB site with a lot of searching facilities was developed with several models for collecting and presentation data for Production Company.
\end{abstract}

Key words: IT, WEB design and WEB presentation, Internet for Business application

\section{INTRODUCTION}

\subsection{Internet in production and business in Bulgaria}

At the present moment when preparations for integration to $\mathrm{EC}$ in Bulgaria are made, problems for use of Internet in production sector, including mechanical engineering, are becoming more and more substantial.

Brief analysis of present situation in Bulgaria, shows that use of Internet in production scope is still very weak. As a illustration of that is the following: only $12 \%$ of the companies participating in 55-th International Technical fair in Plovdiv'99 in Mechanical Engineering Pavilion, had in their advertisements emails and only $2 \%$ had a web page.

The percentages mentioned above have risen tremendously for the last two years only and now they are: $65 \%$ are the companies with e-mail and $38 \%$ companies with WEB pages (fig. 1). 


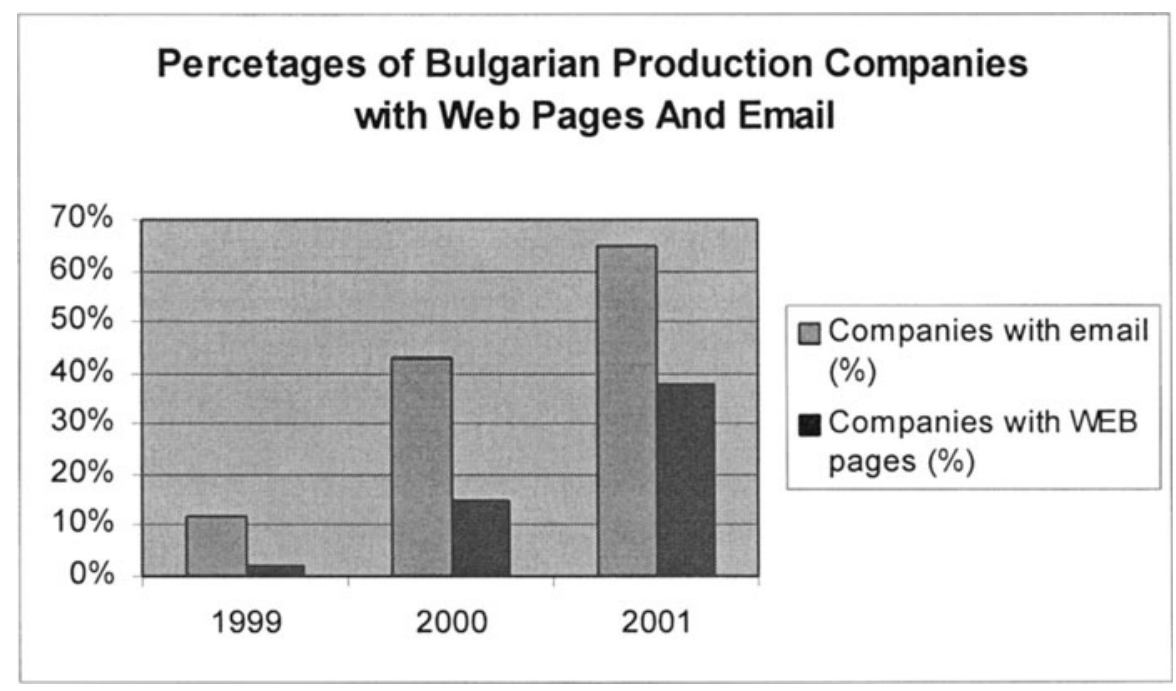

Figure 1. Percentages of Bulgarian Production Companies with Web Pages and Email

At the same time, peoples involved in small and medium business are facing many problems with finding markets for their production, ensuring basic materials for production, participating in actions etc. Internet technology is ideal for all of these, but unfortunately, it is still not used effectively. Why? The answer is: lack of information, lack of habits and abilities for use of enormous opportunities of new Internet technologies in production, trade and services . Simultaneously main part of WEB pages and sites are entertainment oriented.

The existing infrastructure in Bulgaria, especially in small towns, brings up additional problems as: slow speed connections to the Internet, outdated technical equipment etc.

Although there are a big number of search engines in Bulgarian WEB space, most of them are with general orientation. Main disadvantages of that approach are: large amount of search - result pages, lack of technical information in the returned data, limited possibilities for refining the user's query .

Analysing that, project for developing of specialized Internet databases, containing information for products and services of mainly production companies in Bulgaria began 3 years ago. Lecturers from Technical University - Sofia, generated the main idea with financial support provided by private company and Ministry of Economics. This led to development of specialized site - BGCATALOG.COM 


\section{OUR TECHNOLOGY}

The structure of BGCATALOG enables database search in several ways depending on customer's preferences through:

1. Search by product / activity

This search is not only keyword oriented, but also has an advanced feature for choosing the parameters of the searched product / activity. With this option the user can refine his request that is guarantee for fast search and quality results.

2. Search by company's name

New option for choosing the type of the company - trading, production, service, importers/exporters, Ltd., Plc., etc. is under development.

Wildcards also can be used.

3. Search by company's address

The user can use in this search not only the name of the city/village, but also the name of the street, phone number, e-mail etc.

4. Search by branch of the company

Three-level tree structure according to Unified Classification of Republic of Bulgaria was developed, for assisting user's queries.

5. Combination of the mentioned above

For example, ' Production Company for hinge bolts for VW in Sofia '.

Wildcards can be used in every kind of search mentioned above. Logical combinations like 'AND' 'OR' 'NOT' also can be used.

BGCATALOG is organized on two databases - one is the main database with catalogues of the companies and the other is a database with templates for presentation of the company's data. This structure is very flexible and allows different individual design appropriate with demands of each firm and transparent embedding of information from main database in company's WEB-pages. For achieving hi-speed, we use dedicated database - server for access to both databases.

We have developed three different applications for maintain and support of BGCATALOG ' $s$ databases -fig. 2 - WEBASSIST, WEBDESIGN and WEBSEARCH 


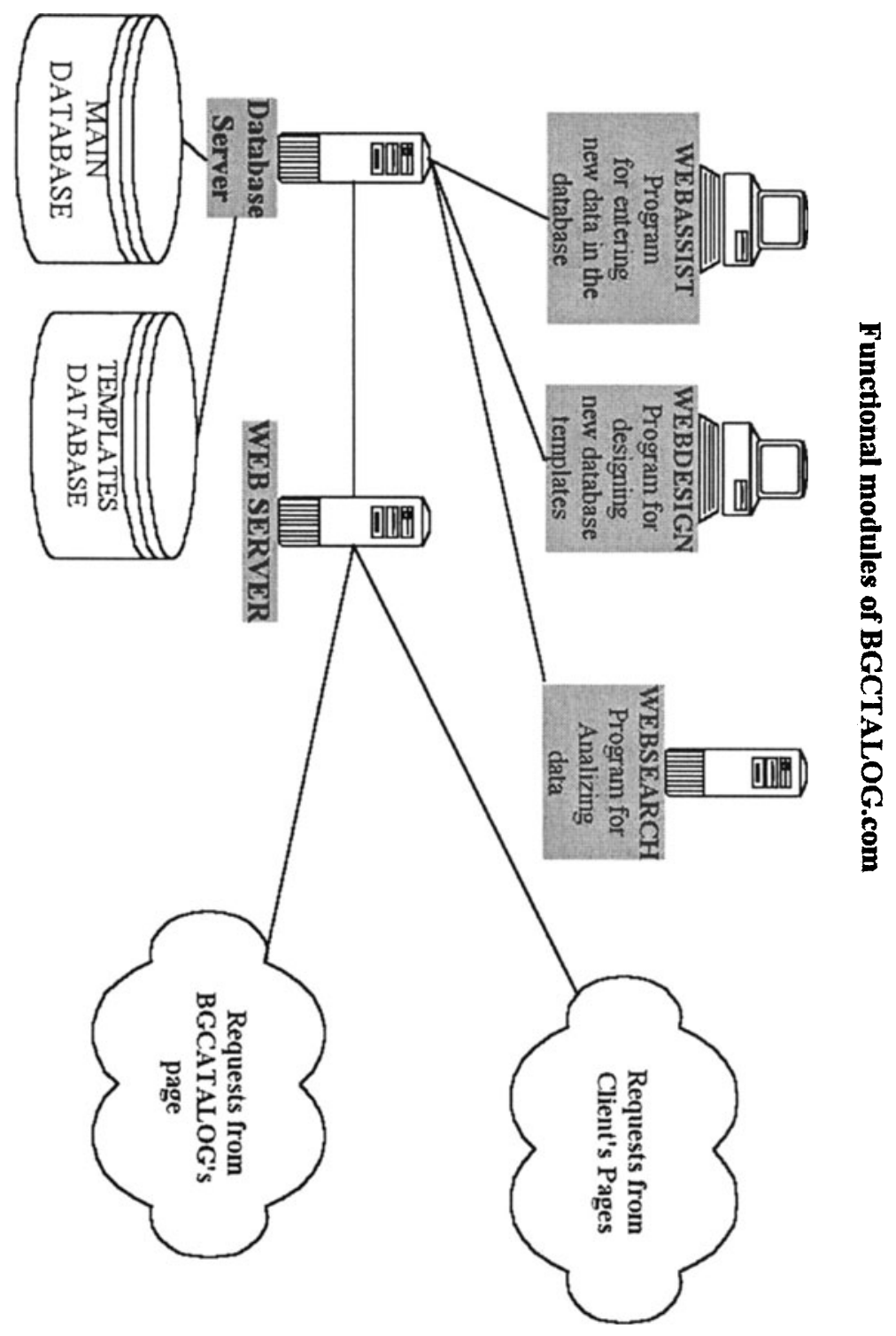

Figure 2. Functional modules of BGCATALOG.COM

WEBASSIST is a program for editing and inserting new information in the main database. It is oriented on six basic models we have developed for collecting information. The program allows speeding - up the process of including and refreshing company's catalogues in the database with it's user friendly interface and table organization with respect to every product and service in each company's list. 
WEBDESIGN is the other application we have developed and it is main purpose to assist designers in making new templates. These templates can be used for full control over presentation of each product/service from the main database. The program is HTML - oriented with many graphical elements and easy of use.

Third program in this range is called WEBSEARCH. It is used for processing inputted data to be suitable for searching. It performs actions like extracting terms in particular branch from company's data, basic morphological analysis of Bulgarian language, spell checking etc. This additional operation on company's data speeds up following WEB -based searches and is used in server-side scripts for increased accuracy of finding.

Final elements of BGCATALOG are shared server-side scripts, which are used for actual WEB - presentation of the companies. These scripts are used both from personal company's WEB pages and from BGCATALOG' s WEB PAGE. They provide different behavior depending on the context thus providing best appearance of the data over INTERNET.

\section{APPROACH FOR COLLECTING INFORMATION FOR DATABASE FOR BGCATALOG}

We have developed six basic models for product presentation for assisting Bulgarian producers in shaping their materials for Internet catalogue.

\subsection{MODEL 1 - Model of WEB page with links to databases}

WWW pages could contain additional information for the company as:

- Name of the company

- Complete address of the company and its representatives - city, ZIP code, street, flat, phone number etc.

- Production opportunities and history of the company

- Participation in international projects, trading with international companies etc.

- Organization structure of the company, company profile etc.

- Links with other WEB pages

- Future plans of the company 
The following models describe presentations of objects in a database and are very useful for manufacturing companies.

\subsection{MODEL 2 - Textual presentation}

This model is suitable for products and services that do not require additional graph materials as picture, images, charts etc.

Information could be structured as follows:

- Branch of the products or services according to the Unified Classification of Republic of Bulgaria

- Brief description of every product or service

\subsection{MODEL 3 - Table presentation with graphics, which is visualized by a user request}

Information could be structured as follows:

- Branch of the products or services according to the Unified Classification of Republic of Bulgaria

- Brief description of every product or service

- Tables with technical parameters for every product or service

- Graphical materials for every product

This type of presentation in the databases is appropriate for products with characteristics, which can be classified in tables. Graphical information for a particular product is viewed on a user request. This model is very suitable for machine building, textile, chemistry and other industrial's products.

\subsection{MODEL 4 - Table presentation with graphics material}

Information could be structured as follows:

- Branch of the products or services according to the Unified Classification of Republic of Bulgaria

- Brief description of every product or service

- Tables with technical parameters of every product or service

- Graphical materials for every product 
In this model, graphic material for every product is visualized in the table with parameters. The model is suitable for the same products as mentioned in the previous model.

\subsection{Model 4 - Textual - graphical presentation}

Information could be structured as follows:

- Branch of the of the products or services according to the Unified Classification of Republic of Bulgaria

- Brief description of every product or service

- Graphical materials for every product

This model is appropriate for products and services, where tabular presentation is not applicable. Each product is accompanied with graphics and text.

\subsection{Model 5 - Summarized graphics for the products, presented in a table form}

Information could be structured as follows:

- Branch of the products or services according to the Unified Classification of Republic of Bulgaria

- Brief description of every product or service

- Tables with technical parameters of every product or service

- General graphic materials

The model is for a big number of products of the same class.

Each model ensures a standard mode for describing the web page's structure and enables variations and individual appearance of every single company.

\section{OUR TARGET GROUP}

Due to our three-year experience, we have gathered huge amount of information for visitors on BGCATALOG' $s$ web page. This gives the idea for the target group of our users. Collected information confirms the original 
orientation to Bulgarian business users. As it may be seen from fig. 3, most of the hits to the WEB page are during working hours of the day in Bulgaria.

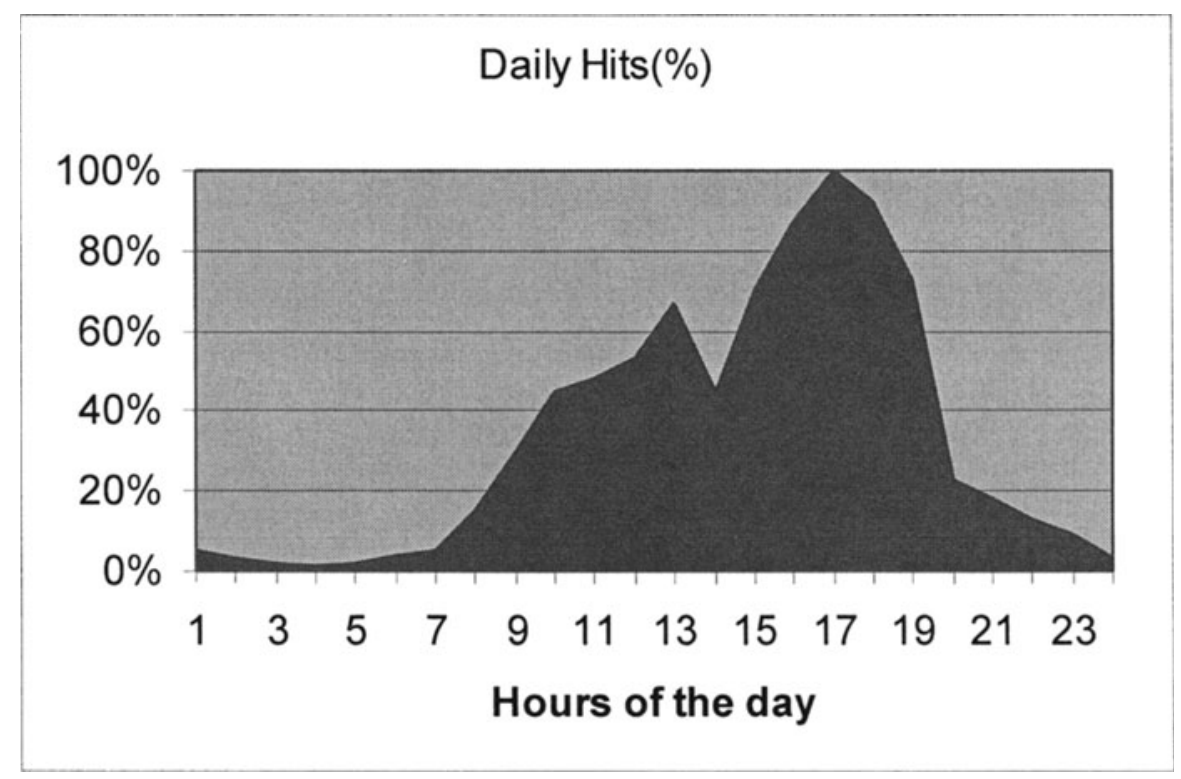

Figure 3. Daily Hits of BGCATALOG

Another confirmation of the business target group is shown on chart 4 it is weekly statistic of hits of the WEB page. 


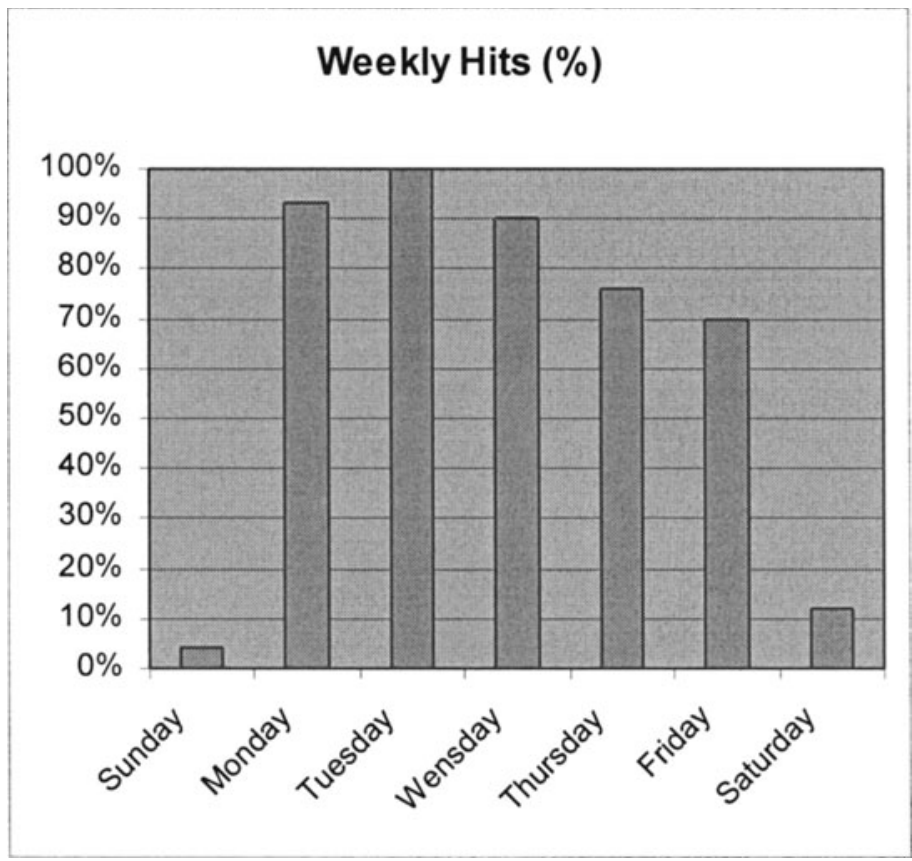

Figure 4. Weekly Hits of BGCATALOG

Another valuable information we have collected for nearly two years are the rate of keywords, which our users have been looking for. This gave to the project new direction for experimental new methods for speeding up the searching process.

The first method of searching is a model without any preliminary processing of the data and it is based on a full-text database search. The speed of the online queries depends entirely from the speed and realization of the searching of the particular database server. Our experiments have shown that this approach ensures stable work, but unfortunately is very slow for big amount of data, especially when this data is structured in many different tables, which is the most common case in technical information.

The next approach is based on a simple preliminary word extracting as a base for subsequent online queries. Here we have small amount of initial work to do before the data is ready for online searching. Several indexes can be added to tables with keywords depending on keywords statistics, alphabetical order etc. The method shows good online speed and minor of preliminary processing.

The last one is more complex - extracting of words followed by their classification as terms by branches. This gives a completely new direction of 
the options for searching as finding related words from particular keyword in specific technical field, pointing the main terms in certain area etc. Disadvantage of this method is the bigger amount of preliminary processing.

Experiments have shown that there is link between speeding up online queries and increasing the time for pre - processing of the data. For an optimal speed of specialized database is very important to find the balance between introductory work over the data and complexity of the online query.

\section{CONCLUSIONS}

Internet technologies have wide application in production sphere. In the near future, they will be used not only for information, advertisement, production catalogues and searchable databases, but also for gathering information data for automation production by use of CNC and PLC etc. Databases with production standards are going to be developed. Huge systems for summarizing of requests and distribution of production over departments, suppliers, stock production etc. through Internet and Intranet are already realized in some big companies.

We consider that good experience of production practice over Internet technologies in machine building should be propagated by:

- Populating of WEB addresses of specialized pages

- Realization of European projects

- Short term qualification courses for personnel and exchange of education materials

All of the above will extend competing of SME, increase quality of production and realization of plans of the company in contemporary fast changing world. 